\title{
Anterior Cervical Discectomy and Fusion: Practice Patterns Among Greek Spinal Surgeons
}

\author{
Savvas L. Spanos ${ }^{\mathrm{a}, \mathrm{b}}$, Ioannis D. Siasios ${ }^{\mathrm{c}, \mathrm{d}}$, Vassilios G. Dimopoulos ${ }^{\mathrm{c}}$, \\ Kostas N. Fountas ${ }^{b}$
}

\begin{abstract}
Background: A web-based survey was conducted among Greek spinal surgeons to outline the current practice trends in regard to the surgical management of patients undergoing anterior cervical discectomy and fusion (ACDF) for degenerative cervical spine pathology. Various practice patterns exist in the surgical management of patients undergoing anterior cervical discectomy for degenerative pathology. No consensus exists regarding the type of the employed graft, the necessity of implanting a plate, the prescription of an external orthotic device, and the length of the leave of absence in these patients.
\end{abstract}

Methods: A specially designed questionnaire was used for evaluating the criteria for surgical intervention, the frequency of fusion employment, the type of the graft, the frequency of plate implantation, the employment of an external spinal orthosis (ESO), the length of the leave of absence, and the prescription of postoperative physical therapy. Physicians' demographic factors were assessed including residency and spinal fellowship training, as well as type and length in practice.

Results: Eighty responses were received. Neurosurgeons represented $70 \%$, and orthopedic surgeons represented $30 \%$. The majority of the participants $(91.3 \%)$ considered fusion necessary. Allograft was the preferred type of graft. Neurosurgeons used a plate in $42.9 \%$ of cases, whereas orthopedic surgeons in $100 \%$. An ESO was recommended for $87.5 \%$ of patients without plates, and in $83.3 \%$ of patients with plates. The average duration of ESO usage was 4 weeks. Physical therapy was routinely prescribed postoperatively by $75 \%$ of the neurosurgeons, and by $83.3 \%$ of the orthopedic surgeons. The majority of

Manuscript accepted for publication May 02, 2016

aDepartment of Physiotherapy, School of Health and Welfare, Central Greece University of Applied Sciences, Lamia, Greece

bDepartment of Neurosurgery, School of Medicine, University of Thessaly, Larissa, Greece

'Department of Neurosurgery, Jacobs School of Medicine and Biomedical Sciences, University at Buffalo, State University of New York, Buffalo, NY, USA ${ }^{\mathrm{d} C}$ Corresponding Author: Ioannis Siasios, University at Buffalo Neurosurgery, 100 High Street, Suite B4, Buffalo, NY 14203, USA.

Email: isiasios@ubns.com

doi: http://dx.doi.org/10.14740/jocmr2572w the participants recommended 4 weeks leave of absence.

Conclusions: The vast majority of participants considered ACDF a better treatment option than an ACD, and preferred an allograft. The majority of them employed a plate, prescribed an ESO postoperatively, and recommended physical therapy to their patients.

Keywords: Anterior cervical discectomy; External orthosis; Fusion; Graft; Physical therapy

\section{Introduction}

Anterior cervical discectomy and fusion (ACDF) constitutes the most commonly performed spinal procedure [1,2]. Despite the high volume of the performed ACDFs, several issues regarding the optimal perioperative and postoperative management of these patients remain controversial [3]. The performance of an intervertebral fusion, the type of the graft, the application of plating, the employment of an external spinal orthosis (ESO), the postoperative employment of physical therapy, as well as the optimal postoperative medical leave of absence remain ill-defined, and highly variable among the published series.

As no formal evidence-based guidelines exist, spinal surgeons are required to develop their own policies, based on their training, possibly their specialty, and their clinical experience [4]. Published studies to date describe the experience of particular individuals and groups, but do not convey an overall rationale for clinical practice policies, and the actual reasoning on which those practice decisions were based [3].

The purpose of our study was to identify and outline the current clinical trends in regard to the surgical and the shortterm postoperative management of patients undergoing ACDF for degenerative cervical spine pathology, and possibly to form a clinical consensus regarding the practice of anterior cervical spine surgery among Greek spinal surgeons.

\section{Materials and Methods}

E-mail invitations were sent to 210 registered spinal surgeons (neurosurgeons and orthopedic surgeons) in Greece, asking 
Table 1. Translated Brief Outline of the Distributed Questionnaire

\begin{tabular}{ll}
\hline Section & Related information \\
\hline Surgeon's background & $\begin{array}{l}\text { Residency training background } \\
\text { Spinal fellowship } \\
\text { Type and length in clinical practice } \\
\text { Practice devoted to spinal surgery }\end{array}$ \\
& $\begin{array}{l}\text { Criteria for ACDF intervention } \\
\text { Frequency of ACDF employment }\end{array}$ \\
Procedure & $\begin{array}{l}\text { Type of the preferred graft } \\
\text { Criteria for graft preference }\end{array}$ \\
Graft & $\begin{array}{l}\text { Criteria for plating application } \\
\text { Frequency of plating application } \\
\text { Plating }\end{array}$ \\
Criteria and length of ESO employment \\
Postoperative care & $\begin{array}{l}\text { Reasons for prescribing physical therapy } \\
\text { Length of medical leave of absence }\end{array}$ \\
\hline
\end{tabular}

them to participate in a web-based survey of current practice in the management of patients undergoing ACDF for degenerative disc disease (disc herniation, spondylosis, radiculopathy, and myelopathy). Surgeons were identified through their registration in the Hellenic Neurosurgical Society, and the Hellenic Spine Society. A second, reminding e-mail was sent approximately 2 months later, in order to maximize their response rate.

All of the participants were asked to complete a specially designed structured questionnaire in Greek (Table 1). This questionnaire evaluated practice patterns associated with their criteria for surgical intervention, the frequency of employment of fusion following anterior cervical discectomy (ACDF vs. ACD), the type of the preferred graft (heterologous vs. autologous), and also the frequency of application of a plate in ACDFs. We also inquired data regarding the employment and the length of an ESO postoperatively. In addition, we gathered information regarding the length of the patients' medical leave of absence postoperatively, and also the prescription of physical therapy post-ACDF to these patients. Furthermore, physicians' demographic factors were assessed in our current survey including residency training background (neurosurgical vs. orthopedic), special fellowship training in spinal surgery, type of practice (academic, private, and NHS), length in clinical practice, and percentage of the responder's practice devoted to spinal surgery.

Data were processed using the Statistical Package for the Social Sciences software, (SPSS version 20, IBM Corporation, NY, USA). The statistical significance of the observed correlation for non-parametric variables was calculated by using the Chi-square methodology. The level of significance was set at $\mathrm{P}$

Table 2. Surgeon's Clinical Experience

\begin{tabular}{llll}
\hline Years in practice & $\begin{array}{l}\text { Neurosurgeons } \\
(\%)\end{array}$ & $\begin{array}{l}\text { Orthopedics } \\
(\%)\end{array}$ & $\begin{array}{l}\text { Total } \\
(\%)\end{array}$ \\
\hline$\leq 10$ & 19.6 & 25 & 21.3 \\
$11-20$ & 44.6 & 16.7 & 36.3 \\
$\geq 21$ & 35.7 & 58.3 & 42.5 \\
\hline
\end{tabular}

of 0.05 , given the descriptive nature of our current study.

\section{Results}

Eighty responses were received from the 210 invited surgeons, yielding a total response rate of 38\%. Neurosurgeons (56/80 participants) represented $70 \%$ of the responders, while the remaining 30\% (24/80 participants) were orthopedic surgeons. Among the responders, $76.3 \%$ had received at least 1 year of structured fellowship training in spinal surgery. Orthopedic surgeons had a spinal fellowship more frequently than neurosurgeons (79.2\% vs. 75\%, respectively); however, this difference did not reach the levels of statistical significance $(\mathrm{P}=$ 0.688). In regard to the clinical experience of the participants, the majority of them $(42.5 \%)$ were in practice for more than 20 years (Table 2$)$. The major part of the participants $(47.5 \%)$ was practicing in the NHS hospitals (Table 3). Anterior cervical procedures represented $13.8 \%$ of the annual surgical volume for the involved neurosurgeons, while the respective percentage for orthopedic surgeons was 5.9\%.

All of the participants considered surgical intervention as the only treatment for cervical radiculopathy and/or myelopathy, while $93.8 \%$ of them based their surgical decision making on both clinical and imaging findings. In regard to the performance of a fusion following anterior cervical discectomy, the vast majority of the participants $(91.3 \%)$ considered fusion necessary. Allograft was the preferred type of graft for accom-

Table 3. Type of Practice

\begin{tabular}{llll}
\hline & $\begin{array}{l}\text { Neurosurgeons } \\
(\%)\end{array}$ & $\begin{array}{l}\text { Orthopedics } \\
(\%)\end{array}$ & $\begin{array}{l}\text { Total } \\
(\%)\end{array}$ \\
\hline NHS & 53.6 & 33.3 & 47.5 \\
Solo private practice & 28.6 & 54.2 & 36.3 \\
Academic position & 16.1 & - & 11.3 \\
\hline Private practice group & - & 8.3 & 2.5 \\
Other & 1.8 & 4.2 & 2.5 \\
\hline
\end{tabular}




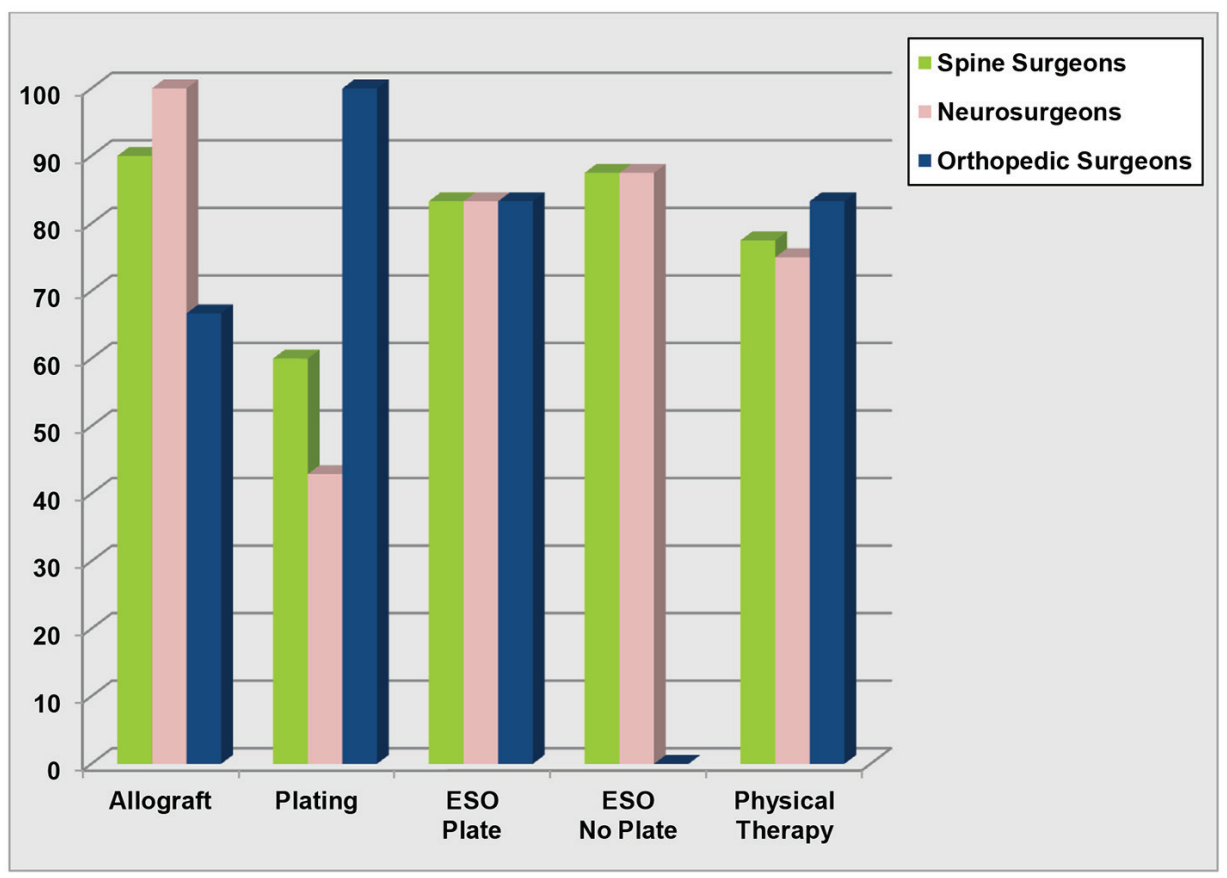

Figure 1. Histogram depicting comparative results between neurosurgeons and orthopedic surgeons in regard to the usage of allograft, the implantation of anterior cervical plate, the prescription of an external spinal orthotic device, and the recommendation for postoperative physical therapy.

plishing osseous fusion in our survey. More specifically, all the neurosurgeons preferred allograft, while 16/24 (66.7\%) orthopedic surgeons used allograft, and only $8 / 24(33.3 \%)$ of them harvested an autograft (Fig. 1). The main argument of the participants for using an allograft was the avoidance of any graft harvesting associated complications, while the major argument for using an autograft was the accomplishment of a more solid osseous fusion and the mitigation of a postoperative pseudoarthrosis. In regard to the employment of plating, $100 \%$ of the participating orthopedic surgeons, and $42.9 \%$ of the responding neurosurgeons indicated that they always used anterior cervical plate (Fig. 1). The major arguments for plating, according to the participants, were the requirement for an efficacious mechanical stabilization $(88.8 \%)$, the preoperative mechanical instability provided by the obtained dynamic imaging studies $(66.3 \%)$, and the usage of an allograft (27.5\%). Analysis of our data revealed no correlation between the clinical experience (years in practice) of the surgeons and the employment of plating, nor any correlation between surgeon's special training (spinal fellowship) and the employment of plating. Moreover, all the surgeons using autograft always used a plate $(8 / 8$ surgeons), while the respective percentage among those using an allograft was 55.6\% (40/72 surgeons). There was a statistically significant correlation $(\mathrm{P}=0.015)$ between the usage of autograft and the employment of an anterior plate in our survey.

Neurosurgeons prescribed an ESO after an ACDF more frequently than orthopedic surgeons, in our survey $(85.7 \%$ vs. $83.3 \%$ respectively). However, this difference did not reach the levels of statistical significance $(\mathrm{P}=0.785)$. A weak trend for prescribing an ESO more frequently among patients with no plate was demonstrated in our survey $(83.3 \%$ vs. $87.5 \%)$, which was not statistically significant $(\mathrm{P}=0.609)$ (Fig. 1). The duration of ESO usage was 4 weeks in the majority of the responders (32.9\%) (mean: 5 weeks, range: 2 - 8 weeks). Physical therapy was routinely prescribed postoperatively by $75 \%$ of the participating neurosurgeons, and by the $83.3 \%$ of the orthopedic surgeons (Fig. 1). The most popular reasons for prescribing physical therapy in our survey were the improvement of the patient's functional outcome $(98.4 \%$ of the responders), and the increase of the patients' upper extremity muscle strength $(88.7 \%$ of the responders).

The majority of the participants $(46.8 \%)$ recommended 4 weeks medical leave of absence (mean: 5.7 weeks, range: 2 - 8 weeks). More specifically, orthopedic surgeons suggested leave of absence in a mean of 5.9 weeks (range: 2 - 8 weeks), while neurosurgeons suggested a mean leave of absence of 5.5 weeks (range: 4 - 8 weeks). In regard to the type of graft and the leave of absence, in the group with allograft, the mean leave of absence was 5.6 weeks (range: 2 - 8 weeks), while among patients with autograft, the mean was 6.3 weeks (range: 4 - 8 weeks). Analysis of our data demonstrated no statistically significant difference between patients with allograft and autograft, in regard to their leave of absence $(P=0.201)$. Likewise, further analysis of our data showed no statistically significant difference between patients with and without plate, in regard to their leave of absence $(\mathrm{P}=0.065)$.

\section{Discussion}

The existence of a wide variation in clinical practice regarding anterior cervical spinal procedures for pathology of degen- 
erative etiology was confirmed by our current study. However, some interesting practice trends emerged from our current survey. The vast majority (93.8\%) of the participants based their decision for surgical intervention both on clinical and imaging findings, while all of them considered surgical treatment as the only therapeutic option for patients with myelopathy and/or radiculopathy. The pertinent literature fully supports this trend, as a growing body of evidence suggests that important factors for surgical decision-making were the physical examination findings, as well as the X-ray, and the MRI findings $[1,5,6]$. Likewise, the vast majority $(91.3 \%)$ of the participants in our survey considered that fusion was advantageous to a discectomy alone. A similar survey performed in the USA documented the same trend among North American spinal surgeons [3]. It has to be mentioned, however, that numerous publications suggest that fusion is not necessary following single- or two-level ACD [7-10]. These series postulate that the advantages of discectomy without a fusion can be summarized into shorter operative time, lower operative blood loss, shorter length of hospital stay, less need for perioperative analgesia, lower surgical cost, and also decreased incidence of intraoperative complications [7-10]. Moreover, there are previously published studies reporting that patient satisfaction and return to preoperative activity were similar between ACD and ACDF groups, although the incidence of fusion was greater in the ACDF group [8, 11]. However, there are other studies reporting that longer followup demonstrates better postoperative function and higher patient's satisfaction with ACDF, than with discectomy alone [2, 12]. It has also been postulated that ACDFs may be advantageous to ACDs in restoring the normal cervical lordosis in patients with abnormal alignment $[7,13,14]$.

In regard to the type of the utilized graft, Greek spinal surgeons (all participating neurosurgeons and more than twothirds of the participating orthopedic surgeons) prefer allograft compared to autograft for achieving an osseous fusion. The reasoning for their preference was the risk of autograft harvesting associated complications. Generally, the issue of the ideal bone graft remains controversial in the literature. Autologous graft, typically harvested from the iliac crest, is generally felt to produce higher rates of fusion, and a lower incidence of graft settling compared to allograft [15-17]. On the other hand, similar fusion rates between allograft and autograft have been reported among non-smokers having single-level ACDF [18]. However, the obtaining of autologous bone graft requires a separate surgical incision with considerable morbidity, and it has been associated with decreased patient's ambulation in the early postoperative period $[19,20]$. In addition, it may produce long-term donor site pain $[21,22]$, although this does not seem to affect the patient's quality of life $[23,24]$. The preference of spinal surgeons on this issue varies significantly from place to place. This geographical variation most probably is related to the financial situation and the structure of the health system in each country. A survey of 118 spinal surgeons in the United Kingdom and Eire found that most $(63 \%)$ of the participants used autologous bone grafts [25]. Similarly, a survey of 60 spinal surgeons in Canada reported that most (76\%) of them used autologous bone grafts for fusion [4]. Another survey performed in India demonstrated that $75 \%$ of the participants preferred an autologous bone graft [26]. The major argument of the autologous bone graft advocates is the high cost of allograft $[4,27]$. However, it has been demonstrated that ACDF with allograft is more cost-effective than that with autograft $[28,29]$.

Orthopedic surgeons always implant an anterior plate in our survey, while approximately $40 \%$ of the participating neurosurgeons prefer a plate in ACDFs. This finding is in accordance with the findings of the USA and the Canadian surveys [3, 4]. The surgeons' background and their specialty may explain these findings. It is widely accepted that orthopedic surgeons have greater exposure to instrumentation in general during their training [4]. In addition, the wide utilization of allograft may influence the employment of a plate, although in our current survey there was a statistically significant correlation between the usage of autograft and the employment of a plate. It has been demonstrated that the application of anterior cervical plate following single-level ACDF with allograft increases the fusion rate $[30,31]$. Theoretically, plating would correlate with greater levels of patient satisfaction, and also with an earlier return to daily activities [4]. Anterior cervical plating is frequently utilized for multilevel discectomies to provide immediate stabilization, buttress the bone graft, reduce the rate of postoperative pseudoarthrosis, and improve and maintain the normal cervical alignment [23, 25, 32-34]. Indeed, Rapoff et al [35] reported that in a cadaveric calf spine model, an anterior cervical plate in a single-level procedure, reduced the magnitude of load transmitted through the graft, and this improved graft consolidation, increasing thus the chance of arthrodesis. Additionally, there are studies reporting better clinical outcome and not significant increase in complication rates with anterior plate fixation in single-level ACDF [32, 36, 37]. These studies also reported significantly decreased rates of graft collapse and absence of any postoperative kyphotic deformities $[32,36,37]$. However, the benefit of plate fixation in singlelevel ACDF remains unproven. Several studies have shown no difference in clinical outcome or fusion rates among patients with or without anterior plate undergoing a single-level ACDF $[38,39]$.

It has to be mentioned that the use of allograft and anterior cervical plate raises substantially the cost of ACDF [4]. In Greece of financial crisis, it is difficult to justify major additional operative costs without evidence of significant improvement in clinical outcome. Nevertheless, there are studies which have provided evidence that, although the short-term costs of ACDF with allograft and plating may be higher than those associated with ACDF with allograft alone or with autograft, the 5 -year cost-effectiveness of these procedures is similar [28, 40]. Further prospective comparative studies may be necessary for addressing the cost issue for specific health systems.

In regard to the employment of ESO postoperatively, $85 \%$ of our participants prescribed one on an average of 5 weeks. The difference between neurosurgeons and orthopedic surgeons ( 85.7 vs. $83.3 \%$, respectively) regarding the postoperative prescription of ESO was minimal. Interestingly, although orthopedic surgeons were more likely to employ anterior cervical plating $(100 \%)$, the vast majority of them $(83.3 \%)$ also recommended ESOs to their patients. This finding is in agreement with the findings of the Canadian survey [4]. There was also a slightly higher prescription rate among patients with no 
plate in our survey ( 87.5 vs. $83.3 \%$ ), as expected, and this finding is in accordance with the Canadian survey, which showed no significant decrease in the ESO employment by using an anterior plate [4]. Traditionally, patients have been placed in an ESO for the initial 4 - 12 postoperative weeks. It is widely accepted that such orthotic devices prevent excessive cervical motion, and thereby help to promote osseous fusion. However, it has to be emphasized that no biomechanical or clinical evidence validates the need for ESO usage following an ACDF [4]. Cauthen et al [41] found no significant difference between the rate of fusion in patients with or without an ESO. It could be postulated that ESO usage reduces postoperative pain, while provides the patient with a sense of security during daily activities. Abbott et al [42] demonstrated in their study that the use of a rigid ESO for 6 weeks is associated with significantly lower neck disability index (NDI) scores and less neck pain.

According to our survey, $75 \%$ of the participating neurosurgeons and $83 \%$ of the orthopedic surgeons prescribed physical therapy to their patients postoperatively. Greek spinal surgeons considered that postoperative physical therapy could improve the patient's functional outcome, and the patient's muscle strength. Several studies have demonstrated greater muscle fatigability and an altered activation pattern among individuals with preoperative pain and cervical osteoarthritic changes, who could be benefited from physical therapy [4345]. Additionally, there are studies indicating significantly increased neck muscle strength and endurance among patients undergoing a physical therapy program after ACDFs [46, 47]. There is evidence that an endurance-strength exercise program is effective in increasing neck muscle strength and activation $[48,49]$. Accordingly, there are numerous studies reporting significant improvement in neck muscle endurance, manual dexterity, hand-grip strength, and improved postoperative NDI scores in patients following a structured physical therapy program including specific training of neck muscles $[47,50]$.

Greek spinal surgeons recommended their patients to return to their work on an average of 5.7 weeks. Minimal difference was found between neurosurgeons and orthopedic surgeons (mean: 5.5 vs. 5.9 weeks, respectively), in our survey. Interestingly, the employment of an anterior plate and also the type of the utilized graft (allograft vs. autograft) did not alter the patients' recovery time and their return to their work.

Our current survey has several weaknesses and limitations. First of all, it carries the weaknesses and the reporting biases of all surveys. Second of all, the response rate was quite low, with only $38 \%$ of the registered spinal surgeons participating in our survey study. Moreover, we compiled our list of spinal surgeons from the registries of the Hellenic Neurosurgical Society and the Hellenic Spine Society. The Hellenic Association of Orthopedic Surgery and Traumatology was not included in our current survey, with the assumption that orthopedic surgeons with an interest in spinal surgery would be members of the Hellenic Spine Society. It is possible however that a limited number of orthopedic surgeons performing spinal procedures were missed in our current survey. It has to be emphasized that our survey focused on the present Greek surgical practice, making no enquiries into imaging, clinical, and functional outcomes. It depicts the current trends in anterior cervical spine surgery for pathology of degenerative origin, providing no data on ef- ficacy of various surgical strategies and/or techniques. Common practice does not necessarily represent the clinically more efficacious or more cost-effective treatment option.

\section{Conclusions}

Our current email-based survey among Greek spinal surgeons regarding their practice patterns in ACDF surgery for degenerative disease demonstrated that the majority of both neurosurgeons and orthopedic surgeons have gone through a special spinal fellowship. All participants considered surgical intervention as the only treatment option for patients with cervical spondylosis, while the vast majority of them based their decision for surgery on both clinical and imaging findings. The vast majority of them (approximately 90\%) considered ACDF better treatment option than an ACD procedure. The majority of the participants preferred allograft than autograft for their osseous fusions. All orthopedic surgeons and approximately $40 \%$ of the participating neurosurgeons employ an anterior plate, while approximately $80 \%$ prescribe an ESO postoperatively and recommend a physical therapy program to their patients. The surgeon's background, the type of the graft, and the implantation of a plate had no influence on the length of the patients' leave of absence.

\section{Conflicts of Interest}

Authors declare that they do not have any conflict of interest in regards to this performed study.

\section{References}

1. Shamji MF, Cook C, Tackett S, Brown C, Isaacs RE. Impact of preoperative neurological status on perioperative morbidity associated with anterior and posterior cervical fusion. J Neurosurg Spine. 2008;9(1):10-16.

2. Nandoe Tewarie RD, Bartels RH, Peul WC. Long-term outcome after anterior cervical discectomy without fusion. Eur Spine J. 2007;16(9):1411-1416.

3. Irwin ZN, Hilibrand A, Gustavel M, McLain R, Shaffer W, Myers M, Glaser J, et al. Variation in surgical decision making for degenerative spinal disorders. Part II: cervical spine. Spine (Phila Pa 1976). 2005;30(19):2214-2219.

4. Pickett GE, Van Soelen J, Duggal N. Controversies in cervical discectomy and fusion: practice patterns among Canadian surgeons. Can J Neurol Sci. 2004;31(4):478483.

5. Lad SP, Patil CG, Berta S, Santarelli JG, Ho C, Boakye M. National trends in spinal fusion for cervical spondylotic myelopathy. Surg Neurol. 2009;71(1):66-69; discussion 69.

6. Alafifi T, Kern R, Fehlings M. Clinical and MRI predictors of outcome after surgical intervention for cervical spondylotic myelopathy. J Neuroimaging. 2007;17(4):315322. 
7. Savolainen S, Rinne J, Hernesniemi J. A prospective randomized study of anterior single-level cervical disc operations with long-term follow-up: surgical fusion is unnecessary. Neurosurgery. 1998;43(1):51-55.

8. Dowd GC, Wirth FP. Anterior cervical discectomy: is fusion necessary? J Neurosurg. 1999;90(1 Suppl):8-12.

9. Savitz MH. Anterior cervical discectomy without fusion or instrumentation: 25 years' experience. Mt Sinai J Med. 2000;67:14-17.

10. Sheth JH, Patankar AP, Shah R. Anterior cervical microdiscectomy: is bone grafting and in-situ fusion with instrumentation required? Br J Neurosurg. 2012;26(1):1215.

11. Hauerberg J, Kosteljanetz M, Boge-Rasmussen T, Dons K, Gideon P, Springborg JB, Wagner A. Anterior cervical discectomy with or without fusion with ray titanium cage: a prospective randomized clinical study. Spine (Phila $\mathrm{Pa}$ 1976). 2008;33(5):458-464.

12. Thorell W, Cooper J, Hellbusch L, Leibrock L. The longterm clinical outcome of patients undergoing anterior cervical discectomy with and without intervertebral bone graft placement. Neurosurgery. 1998;43(2):268-273; discussion 273-264.

13. Faldini C, Leonetti D, Nanni M, Di Martino A, Denaro L, Denaro V, Giannini S. Cervical disc herniation and cervical spondylosis surgically treated by Cloward procedure: a 10-year-minimum follow-up study. J Orthop Traumatol. 2010;11(2):99-103.

14. Verhagen AP, van Middelkoop M, Rubinstein SM, Ostelo R, Jacobs W, Peul W, Koes BW, et al. Effect of various kinds of cervical spinal surgery on clinical outcomes: a systematic review and meta-analysis. Pain. 2013;154(11):2388-2396.

15. Floyd T, Ohnmeiss D. A meta-analysis of autograft versus allograft in anterior cervical fusion. Eur Spine J. 2000;9(5):398-403.

16. Lofgren H, Johannsson V, Olsson T, Ryd L, Levander B. Rigid fusion after cloward operation for cervical disc disease using autograft, allograft, or xenograft: a randomized study with radiostereometric and clinical followup assessment. Spine (Phila Pa 1976). 2000;25(15):19081916.

17. Klein GR, Vaccaro AR, Albert TJ. Health outcome assessment before and after anterior cervical discectomy and fusion for radiculopathy: a prospective analysis. Spine (Phila Pa 1976). 2000;25(7):801-803.

18. Malloy KM, Hilibrand AS. Autograft versus allograft in degenerative cervical disease. Clin Orthop Relat Res. 2002;394:27-38.

19. Faldini C, Chehrassan M, Miscione MT, Acri F, d'Amato M, Pungetti C, Luciani D, et al. Single-level anterior cervical discectomy and interbody fusion using PEEK anatomical cervical cage and allograft bone. J Orthop Traumatol. 2011;12(4):201-205.

20. Miller LE, Block JE. Safety and effectiveness of bone allografts in anterior cervical discectomy and fusion surgery. Spine (Phila Pa 1976). 2011;36(24):2045-2050.

21. Goulet JA, Senunas LE, DeSilva GL, Greenfield ML. Autogenous iliac crest bone graft. Complications and func- tional assessment. Clin Orthop Relat Res. 1997;339:7681.

22. Dimitriou R, Mataliotakis GI, Angoules AG, Kanakaris NK, Giannoudis PV. Complications following autologous bone graft harvesting from the iliac crest and using the RIA: a systematic review. Injury. 2011;42(Suppl 2):S315.

23. Wright IP, Eisenstein SM. Anterior cervical discectomy and fusion without instrumentation. Spine (Phila Pa 1976). 2007;32(7):772-774; discussion 775.

24. Skeppholm M, Olerud C. Pain from donor site after anterior cervical fusion with bone graft: a prospective randomized study with 12 months of follow-up. Eur Spine J. 2013;22(1):142-147.

25. Harland SP, Laing RJ. A survey of the peri-operative management of patients undergoing anterior cervical decompression in the UK and Eire. Br J Neurosurg. 1998;12(2):113-117.

26. Abrishamkar S, Karimi Y, Safavi M, Tavakoli P. Single level cervical disc herniation: A questionnaire based study on current surgical practices. Indian J Orthop. 2009;43(3):240-244

27. Casey AT. Bone grafts and anterior cervical discectomy lack of evidence, but no lack of opinion. Br J Neurosurg. 1999;13(5):445-448.

28. Angevine PD, Zivin JG, McCormick PC. Cost-effectiveness of single-level anterior cervical discectomy and fusion for cervical spondylosis. Spine (Phila Pa 1976). 2005;30(17):1989-1997.

29. Bhadra AK, Raman AS, Casey AT, Crawford RJ. Singlelevel cervical radiculopathy: clinical outcome and costeffectiveness of four techniques of anterior cervical discectomy and fusion and disc arthroplasty. Eur Spine J. 2009;18(2):232-237.

30. Samartzis D, Shen FH, Goldberg EJ, An HS. Is autograft the gold standard in achieving radiographic fusion in one-level anterior cervical discectomy and fusion with rigid anterior plate fixation? Spine (Phila Pa 1976). 2005;30(15):1756-1761.

31. Kaiser MG, Haid RW, Jr., Subach BR, Barnes B, Rodts GE, Jr. Anterior cervical plating enhances arthrodesis after discectomy and fusion with cortical allograft. Neurosurgery. 2002;50(2):229-236; discussion 236-228.

32. Katsuura A, Hukuda S, Imanaka T, Miyamoto K, Kanemoto M. Anterior cervical plate used in degenerative disease can maintain cervical lordosis. J Spinal Disord. 1996;9(6):470-476.

33. Epstein NE. Anterior cervical diskectomy and fusion without plate instrumentation in 178 patients. J Spinal Disord. 2000;13(1):1-8.

34. Wang JC, McDonough PW, Kanim LE, Endow KK, Delamarter RB. Increased fusion rates with cervical plating for three-level anterior cervical discectomy and fusion. Spine (Phila Pa 1976). 2001;26(6):643-646; discussion 646-647.

35. Rapoff AJ, O'Brien TJ, Ghanayem AJ, Heisey DM, Zdeblick TA. Anterior cervical graft and plate load sharing. J Spinal Disord. 1999;12(1):45-49.

36. Wang JC, McDonough PW, Endow K, Kanim LE, De- 
lamarter RB. The effect of cervical plating on single-level anterior cervical discectomy and fusion. J Spinal Disord. 1999;12(6):467-471.

37. Bose B. Anterior cervical instrumentation enhances fusion rates in multilevel reconstruction in smokers. J Spinal Disord. 2001;14(1):3-9.

38. Connolly PJ, Esses SI, Kostuik JP. Anterior cervical fusion: outcome analysis of patients fused with and without anterior cervical plates. J Spinal Disord. 1996;9(3):202206.

39. Samartzis D, Shen FH, Lyon C, Phillips M, Goldberg EJ, An HS. Does rigid instrumentation increase the fusion rate in one-level anterior cervical discectomy and fusion? Spine J. 2004;4(6):636-643.

40. Carreon LY, Anderson PA, Traynelis VC, Mummaneni PV, Glassman SD. Cost-effectiveness of single-level anterior cervical discectomy and fusion five years after surgery. Spine (Phila Pa 1976). 2013;38(6):471-475.

41. Cauthen JC, Kinard RE, Vogler JB, Jackson DE, DePaz OB, Hunter OL, Wasserburger LB, et al. Outcome analysis of noninstrumented anterior cervical discectomy and interbody fusion in 348 patients. Spine (Phila $\mathrm{Pa}$ 1976). 1998;23(2):188-192.

42. Abbott A, Halvorsen M, Dedering A. Is there a need for cervical collar usage post anterior cervical decompression and fusion using interbody cages? A randomized controlled pilot trial. Physiother Theory Pract. 2013;29(4):290-300.

43. Lee H, Nicholson LL, Adams RD. Neck muscle endurance, self-report, and range of motion data from subjects with treated and untreated neck pain. J Manipulative Physiol Ther. 2005;28(1):25-32.
44. Falla D, Rainoldi A, Merletti R, Jull G. Myoelectric manifestations of sternocleidomastoid and anterior scalene muscle fatigue in chronic neck pain patients. Clin Neurophysiol. 2003;114(3):488-495.

45. Falla D, Jull G, Edwards S, Koh K, Rainoldi A. Neuromuscular efficiency of the sternocleidomastoid and anterior scalene muscles in patients with chronic neck pain. Disabil Rehabil. 2004;26(12):712-717.

46. Ylinen JJ, Savolainen S, Airaksinen O, Kautiainen H, Salo P, Hakkinen A. Decreased strength and mobility in patients after anterior cervical diskectomy compared with healthy subjects. Arch Phys Med Rehabil. 2003;84(7):1043-1047.

47. Peolsson A, Kjellman G. Neck muscle endurance in nonspecific patients with neck pain and in patients after anterior cervical decompression and fusion. J Manipulative Physiol Ther. 2007;30(5):343-350.

48. Falla D, Jull G, Hodges P, Vicenzino B. An endurancestrength training regime is effective in reducing myoelectric manifestations of cervical flexor muscle fatigue in females with chronic neck pain. Clin Neurophysiol. 2006;117(4):828-837.

49. Jull GA, Falla D, Vicenzino B, Hodges PW. The effect of therapeutic exercise on activation of the deep cervical flexor muscles in people with chronic neck pain. Man Ther. 2009;14(6):696-701.

50. Peolsson A, Soderlund A, Engquist M, Lind B, Lofgren $\mathrm{H}$, Vavruch L, Holtz A, et al. Physical function outcome in cervical radiculopathy patients after physiotherapy alone compared with anterior surgery followed by physiotherapy: a prospective randomized study with a 2-year follow-up. Spine (Phila Pa 1976). 2013;38(4):300-307. 